\title{
Reproductive endocrinology of wild, long-lived raptors
}

\author{
Julio Blas ${ }^{\mathrm{a}, *}$, Lidia López ${ }^{\mathrm{a}}$, Alessandro Tanferna ${ }^{\mathrm{a}, \mathrm{b}}$, Fabrizio Sergio ${ }^{\text {a }}$, Fernando Hiraldo ${ }^{\text {a }}$ \\ ${ }^{a}$ Department of Conservation Biology, Estación Biológica de Doñana, C.S.I.C. Apdo 1056, E-41013 Sevilla, Spain \\ ${ }^{\mathrm{b}}$ Dipartimento delle Scienze dell'Uomo, dell'Ambiente e della Natura. University of Urbino - Loc. Crocicchia 61029, Urbino (PU), Italy
}

Keywords:

Accipitridae

Black kite

Estradiol

Milvus migrans

Parental care

Progesterone

Reproduction

Sex steroids

Sexual function

Sexual selection

Testosterone

\begin{abstract}
a b s t r a c t
The last decades have witnessed a surge of studies analyzing the role of sex hormones on the behavior and ecology of wild bird populations, allowing a more integrated view of the evolution of avian physiology and life histories. Despite a marked progress, field studies show a considerable bias towards research on specific phylogenetic groups, neglecting a significant fraction of the class Aves. Here we analysed changes in the circulating levels of sex steroids in relation to reproductive behaviour in wild black kites (Milvus migrans), a long-lived and socially monogamous Accipitridae raptor. Males and females displayed a single seasonal peak of circulating testosterone (males) and estradiol (females) during pre-laying and laying. Absolute male testosterone levels were low even at the seasonal maximum and remained below detection limits in females. The latter results supports the idea that avian species establishing long-term pair bonds require lower amounts of circulating androgens for reproduction. Circulating progesterone showed a single seasonal peak in females and males, but their timing (during Incubation and Post-brooding respectively) did not overlap. The fact that females black kites perform the majority of incubation and males provide the majority of care to fledglings suggests that progesterone is involved in the expression of parental behaviors.
\end{abstract}

\section{Introduction}

Sex steroids regulate and synchronize fundamental aspects of reproduction in vertebrates, from gonadal recrudescence and production of fertile gametes to the development of specific morphological and behavioral traits (Wingfield and Farner, 1993; Wingfield, 1983; Blas et al., 2006; Nelson, 2005). The last two decades have witnessed a considerable surge of studies analyzing the role of sex hormones on the behavior and ecology of wild bird populations, allowing a more integrated view of the evolution of avian physiology and life histories (Maney, 2008; Wingfield, 2008). As a consequence, it is now well established that systemic changes in gonadal steroid levels regulate sexual function in a cyclic manner, adjusting the physiology, morphology and behavior of the individuals as a function of the reproductive strategies (Steiger et al., 2006; Wingfield and Farner, 1993; Wingfield and Silverin, 2002; Wingfield et al., 2008).

Despite such marked progress, field studies show a considerable bias to conduct research on specific hormones and phylogenetic groups, with song birds (i.e. Passeriformes) and testosterone (mostly in males) being the preferred study models. Such bias neglects a significant fraction of the class Aves, a vertebrate group

\footnotetext{
* Corresponding author. Fax: +34 954621125.

E-mail addresses: julioblas@ebd.csic.es, julioblas@terra.es (J. Blas).
}

characterized by an extraordinarily rich evolutionary radiation and diversity in morphological, behavioural and physiological adaptations. As a consequence, the interplay between sex hormones and reproduction remains largely unexplored in most avian families, with the Accipitridae raptors being one of the least studied groups. In fact, the hormonal basis of reproduction in wild Accipitridae birds has been studied in only one species, despite the fact that such family comprises over 500 taxa (del Hoyo et al., 1994). Almost two decades ago, Mays et al. (1991) analyzed seasonal changes of sex steroids levels in relation to helping behavior in Harriś hawks (Parabuteo unicinctus). Therefore, all our knowledge on endocrine function for this avian group comes from a species that has the unusual feature within the family of breeding cooperatively. Because many raptor populations are experiencing anthropogenic impacts in the form of poison and toxic contamination, a contribution to understand their reproductive physiology could provide foundations for applied studies (e.g. endocrine disruption, Baos and Blas, 2009; Blas and Baos, 2008) and for the management of wild populations.

The present study is aimed at analyzing the endocrine basis of reproduction in a long-lived, migratory, sexually monochromatic and socially monogamous raptor: the black kite (Milvus migrans). The lack of previous information on the endocrine profiles of Accipitridae birds lead us to formulate a number of predictions (see Table 1) based on research performed in other avian models: 

Table 1

Eco-physiological hypotheses explaining patterns of sex steroid production in birds. Predictions (in italics) are adapted to our study model, a seasonal breeding and single brooded avian species establishing long-term pair bonds.

\begin{tabular}{|c|c|}
\hline Hypotheses & Predictions \\
\hline 1. Seasonal pattern & $\begin{array}{l}\text { Sex steroid levels mirror seasonal changes of gonadal development and sexual activity } \\
\text { 1a. Systemic elevations of sex steroids (T, E) during Pre-laying and Laying } \\
\text { 1b. Systemic decrease of sex steroids (T, E) by the end of the breeding season }\end{array}$ \\
\hline 2. Parental behavior & $\begin{array}{l}\text { Elevated testosterone levels inhibit parental behaviour } \\
\text { 2a. Systemic decrease of sex steroids (T) after Laying }\end{array}$ \\
\hline 3. Number of cycles & $\begin{array}{l}\text { The number of cycles of increase and decrease in sex steroid levels mirror the number of clutches within a reproductive season (T, E) } \\
\text { 3a. Males (T) and females (E) will show a single cycle of sex steroid levels }\end{array}$ \\
\hline 4. Pair bonds & $\begin{array}{l}\text { Absolute levels of sex steroids }(\mathrm{T}) \text { at seasonal maximum reflects the strength of pair bonds } \\
\text { 4a. The absolute levels of testosterone (T) will be low }\end{array}$ \\
\hline
\end{tabular}

Notes: T: testosterone levels in males, E: estradiol levels in females.

(1) Vernal elevations: Seasonal breeding species typically show yearly cycles of gonadal growth at the start of the breeding season, which are mirrored by systemic elevations in testosterone and estradiol (Heath et al., 2003; Wingfield and Farner, 1993). As seasonal breeders, black kites start reproductive activities in March upon arrival to the breeding territories from their African wintering quarters (Sergio et al., 2007a; Cramp and Simmons, 1980). Therefore, we may predict systemic elevations of testosterone and estradiol upon arrival in males and females respectively, during the early stages of the breeding season corresponding to territory acquisition, mating, nest building and fertilizations (Fig. 1).

(2) Post-laying decrease: Following the sexual stages of the breeding cycle, avian species typically start gonadal regression. This process is accompanied by a progressive decrease in the levels of circulating testosterone and estradiol. Testosterone is expected to decrease soon after the sexual phase in monogamous species if this hormone inhibits parental behaviour (Steiger et al., 2006; Wingfield et al., 2001; McQuenn et al., 1999). Therefore, as a monogamous species we expect male black kites to show a decrease in testosterone as they perform parental activities (i.e. hypothesis 2, Table 1).

(3) Number of seasonal peaks: According to the arguments above, avian species laying several clutches along a breeding season typically show multiple cycles of elevation and decrease in sex steroid levels (Wingfield and Farner, 1993). Because black kites lay only one clutch per year, we expect them to display a single peak of circulating testosterone and estradiol.

(4) Absolute levels of circulating steroids: Birds show a considerable inter-species variability in absolute levels of circulating sex steroids, even at their seasonal maximum (Wingfield and Farner, 1993). Such variability has been posited to reflect the strength of pair bonds, with those species changing mates among subsequent reproductions showing higher titres compared to species that maintain the same mate (Mays et al., 1991). Because black kites display very high rates of inter-year fidelity to territories and mates (Forero et al., 1999), we predicted low levels of circulating sex steroids during the seasonal maximum.

Although the above predictions regarding patterns of sex steroid levels are mainly related to testosterone and estradiol (see Table 1), progesterone may also play a relevant role in physiology and behavior. However, the function of progesterone in avian reproduction remains poorly understood (Davis et al., 1995; Hirschenhauser et al., 1999; Heath et al., 2003). While some studies report no significant changes in progesterone levels during the breeding season (Fivizzani and Oring, 1986; Hector and Goldsmith, 1985; Heath et al., 2003), others suggest that this hormone stimulates incubation (Davis et al., 1995; Fivizzani and Oring, 1986; Silver and Cooper, 1993) or chick brooding (Hector et al., 1996). The inconsistency among studies prevent us from making any a priori prediction.

To test hypotheses 1-4 and explore changes in progesterone levels during the reproductive cycle, we monitored the breeding activities of wild, individually banded black kites. To do so, we combined field observations in a long-term monitored population in south-western Spain with the periodic collection of blood samples along the sequential life history stages that characterize reproduction (Fig. 1).

\section{Methods}

\subsection{Study species and population}

Black kites (M. migrans) are medium-sized, socially monogamous, sexually monochromatic (Fig. 1) migratory raptors present

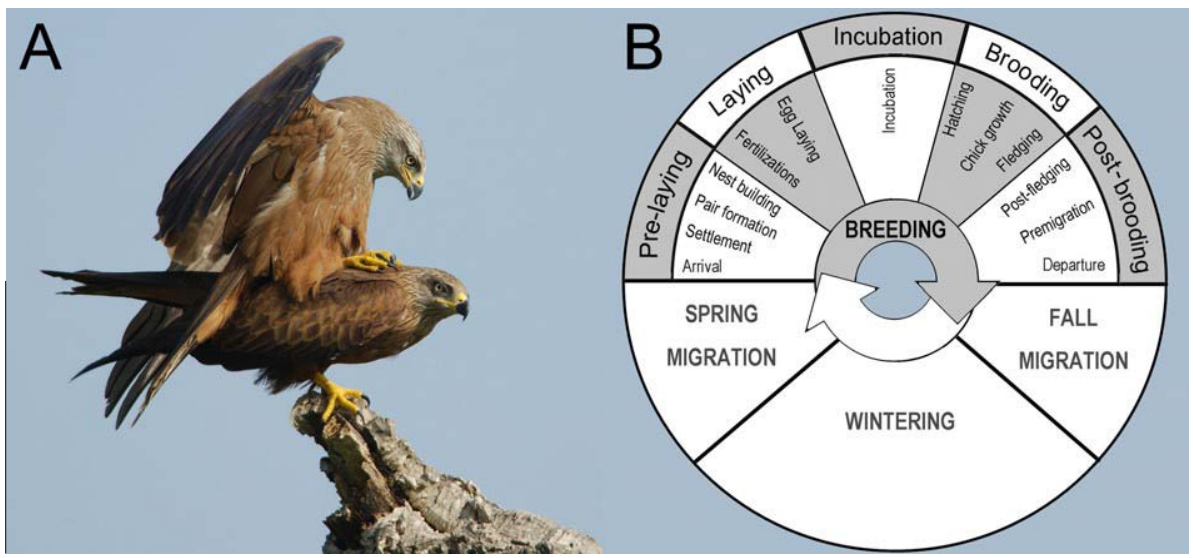

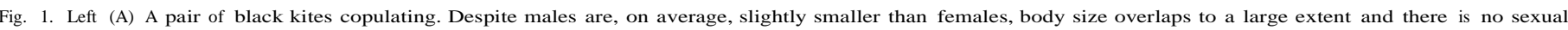

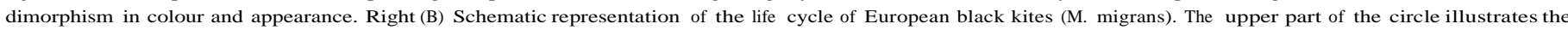

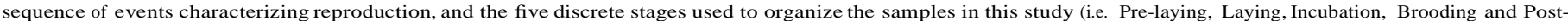
brooding). Note that a given stage can involve one or more sub-stages (e.g. the Laying stage includes the sub-stages of fertilizations and egg laying). 
in their European breeding grounds from early March to late August (Sergio et al., 2007a,b; Cramp and Simmons, 1980). In the study area (Doñana National Park, Southwest Spain), the kite population is composed of c.a. 500 breeding pairs (Sergio et al. 2005). Since 1965 this population has been subjected to scientific monitoring and from 1986 onwards nestlings have been periodically banded with alphanumeric-coded rings, which can be read by spotting scopes without disturbing the birds. Longevity records indicate that birds in this population may reach 26 years of age (Blas and Hiraldo, 2010; Blas et al., 2009). Natal dispersal distances are very short (i.e. median $4800 \mathrm{~m}$ ), and extensive surveys indicate the absence of emigration to other populations (Forero et al., 1999; Forero et al., 2002). After first breeding, kites tend to maintain the same territory and mate, with breeding dispersal distances taking place in areas in the vicinity (median distance $302 \mathrm{~m}$, Forero et al., 1999). Marked territory holders were searched on a yearly basis since 1992 by means of continuous field surveys from early March to late June. When a banded bird was detected on a territory, the area was visited several times to locate its nest and monitor reproductive activities (see below).

\subsection{Bird capture, sampling and laboratory analyses}

Between early March 1997 and late July 1998 we captured black kites using baited cannon nets. Based on behavioral observations accumulated prior to and after capture, we selected 93 breeding birds (43 males and 50 females) temporally distributed along each of the breeding stages characterizing the reproductive season (Fig. 1). A 1 ml-blood sample was collected from the brachial vein to determine circulating levels of testosterone, estradiol and progesterone. Collected blood samples were maintained in coolers and centrifuged the same day for separation of plasma, which was stored frozen $\left(-80^{\circ} \mathrm{C}\right)$ until performing determinations of hormone levels. Our field methods did not cause casualties or damage to the birds, all the capture and sampling protocols were performed in concert with Spanish laws and we prioritized ethical considerations over scientific goals.

Because male and female black kites look alike (Fig. 1), the cellular fractions of the blood samples were preserved in ethanol and subjected to molecular analyses for sex determination. Following Ellegren (1996) we performed a PCR multiplex amplification of DNA fragments located in the CHD gen using the primers 3224R (E1), cfr (E2) and 2945F (E3).

Plasma testosterone concentrations were determined in duplicate tubes through enzyme linked immunoassay, following procedures described in the commercial kits Fertigenix-Testo-Easia (Biosource Europe, Nivelles, Belgium; product 40-170-00; recently changed to KAP1701 by DIAsource ImmunoAssays, Nivelles, Belgium) as in Elbetieha and Da'as (2003). The minimum detection limit of the assay, defined as the dose of testosterone which produced a relative binding $(\% \mathrm{~B} / \mathrm{Bo})$ of $80 \%(\mathrm{ED} 80)$, was $70 \mathrm{pg} / \mathrm{ml}$. Assay variability $(n=3)$ was determined as the \%coefficient of variation $(\% \mathrm{CV})$ resulting from repeated measurement of aliquots from a pool of black kite plasma $(n=2)$ in each assay. Intra and inter-assay coefficients of variation were $<19 \%$ and $<23 \%$, respectively. Serial dilutions of the black kite plasma generated a displacement curve parallel to the testosterone standard curve. Plasma estradiol and progesterone concentrations were assayed in duplicate through solid-phase fluoroinmunoassays (see e.g. Blas and Hiraldo, 2010), following the manufacture procedures of AutoDELFIA ${ }^{\circledR}$ Progesterone Kit (Wallac-PerkinElmer Life and Analytical Sciences, Turku, Finland; product B066-101) and AutoDELFIA ${ }^{\circledR}$ Estradiol Kit (Wallac-PerkinElmer Life and Analytical Sciences, Turku, Finland; product B056-101). The minimum detection limits of the assays, defined as the dose which produced a relative binding $(\% \mathrm{~B} / \mathrm{Bo})$ of $80 \%$ (ED80), were $13 \mathrm{pg} / \mathrm{ml}$ (estradiol) and $300 \mathrm{pg} / \mathrm{ml}$ (progesterone). Assay variability for estradiol $(n=3)$ and progesterone $(n=4)$ were determined as the \%coefficient of variation $(\% \mathrm{CV})$ resulting from repeated measurement of aliquots from a pool of kite plasma $(n=2)$ in each assay. Intra and inter-assay coefficients of variation were respectively $<5 \%$ and $<21 \%$ for estradiol, and $<24 \%$ and $<33 \%$ for progesterone. Serial dilutions of the kite plasma generated displacement curves parallel to the standard curves. Sample position was randomized within and between assays. For statistical purposes, non-detectable samples were assumed to have steroid concentrations equal to the detection limits of the assays (e.g. Hau et al., 2000; Blas and Hiraldo, 2010).

\subsection{Characterization of reproductive stages}

Plastic alphanumeric bands allowed individual monitoring of reproductive activities in the sampled birds (Sergio et al., 2007a; Blas et al., 2009; Sergio et al., 2009). By means of combining behavioural observations and periodic visits to nests, we organized blood samples into five categories (i.e. Pre-laying, Laying, Incubation, Brooding and Post-brooding; see Fig. 1) matching the discrete stages that characterize the reproductive biology of the species (Bustamante and Hiraldo, 1989; Viñuela, 1991; Viñuela and Bustamante, 1992; Viñuela and Ferrer, 1997; see Blas and Hiraldo, 2010 for details). We defined as Laying stage the period of fertilizations and egg laying. Although black kites copulate throughout the breeding season (Koga and Shiraishi, 1994; Negro and Grande, 2001) fertile copulations concentrate from 12 days prior to egg laying until clutch completion (Bird and Buckland, 1976; Mougeot, 2000). When the exact time of egg laying was not directly recorded by observation of nest contents, we subtracted a 30-day period from the hatching date (i.e. the incubation period, Viñuela, 1991; Viñuela and Ferrer, 1997) which could be calculated according to a regression analysis using the nestlingś wing chord (Viñuela and Bustamante, 1992). Blood samples obtained before the Laying stage, were assigned to a Pre-laying stage. This category included birds recently arrived at the breeding grounds, typically performing nest building and nuptial feeding (Fig. 1). The following stage we defined was Incubation, which lasts 30 days (Viñuela, 1991; Viñuela and Ferrer, 1997). Samples collected after incubation were assigned to the Brooding stage, which lasts about 48 days (Bustamante and Hiraldo, 1989). After this period, samples were assigned to a Post-brooding stage (Fig. 1). During this period the fledglings are still dependent on parental care for food and defence (Bustamante and Hiraldo, 1989), but may also start to prepare for migration by roaming progressively farther from their territory and eventually joining communal roosts.

\subsection{Statistical analyses}

Changes in circulating levels of sex steroids were analyzed separately in males and females, considering breeding stage as a factor. Before conducting statistical analyses we tested the normality of the response variables. When the response variable was not normally distributed and normality could not be achieved using logarithmic transformations, we used Generalised Linear Model GLMs (McCullagh and Nelder, 1989) with gamma distribution of errors and logarithmic link functions, upon verification of a significant fit to the exponential distribution. Otherwise GLMs were constructed using normal distributions of errors and identity link functions, following McCullagh and Nelder (1989).

\section{Results}

Circulating levels of testosterone in male black kites $(n=43)$ showed strong seasonal fluctuations, with elevated titres characterizing the early stages of the reproductive cycle (i.e. Pre-laying 
and Laying), followed by gradual decreases (Fig. 2). The distribution of errors of testosterone levels showed significant deviations from normality but a good fit to the exponential distribution, justifying the use of GLMs with gamma error and logarithmic link function. Temporal fluctuations were statistically significant $\left(\mathrm{V}_{4}{ }_{4}=32.60, \mathrm{P}<0.01\right)$, with circulating testosterone being high and similar during the first two study periods $\left(\mathrm{v}^{2}{ }_{1}=0.84\right.$, $\mathrm{P}=0.36$ for the contrast between Pre-laying and Laying) and remaining similarly low from Incubation to Post-brooding $\left(\mathrm{V}_{2}{ }_{2}=2.82, \mathrm{P}=0.24\right)$. The elevated titres recorded during the early stages of the reproductive cycle were significantly higher than those recorded after Laying $\left(\mathrm{V}^{2}{ }_{1}=30.82, \mathrm{P}<0.01\right.$ for the contrast between Pre-laying and Laying with the subsequent stages).

With regard to female black kites, testosterone levels were below detection limits of the assay in all the samples. Estradiol titres $(\mathrm{n}=50)$ showed seasonal fluctuations (Fig. 3) that resembled the pattern of testosterone in males. The multivariant analysis (GLM with exponential errors and logarithmic link function) revealed a significant effect of reproductive stage $\left(\mathrm{v}_{4}^{2}=90.59, \mathrm{P}<0.01\right)$. Circulating estradiol was elevated during Pre-laying and Laying $\left(\mathrm{V}^{2}{ }_{1}=0.95, \mathrm{P}=0.33\right.$ ), decreased during Incubation (showing lower concentrations compared to Laying: $\mathrm{V}^{2}=13.21$, $\mathrm{P}<0.01$; but similar to Pre-laying: $\mathrm{v}^{2}{ }_{1}=2.02, \quad \mathrm{P}=0.16$ ), and remained low afterwards.

Following logarithmic transformation, the distribution of frequencies for the circulating concentration of progesterone did not show deviations from normality, justifying the use of GLMs with normal distribution and identity link function. Among males ( $\mathrm{n}=33$ ), progesterone levels increased gradually along the reproductive cycle $\left(\mathrm{v}_{4}{ }_{4}=15.51, \mathrm{P}<0.01\right.$; Fig. 4$)$, with minimum levels during Pre-laying and maximum titres during the Post-brooding stage $\left(\mathrm{V}_{1}{ }_{1}=7.34, \mathrm{P}<0.01\right.$ for the contrast between Post-brooding and all the other stages grouped). Although progesterone levels were statistically similar during Brooding and Post-brooding $\left(\mathrm{V}^{2}{ }_{1}=3.35, \mathrm{P}=0.07\right)$, both stages differed from all the others periods combined $\left(\mathrm{V}^{2}{ }_{1}=10.23, \mathrm{P}<0.01\right)$. In females, circulating progesterone levels significantly differed between reproductive stages $\left(\mathrm{n}=47, \mathrm{v}_{4}^{2}=9.63, \mathrm{P}<0.05\right)$. However, rather than showing

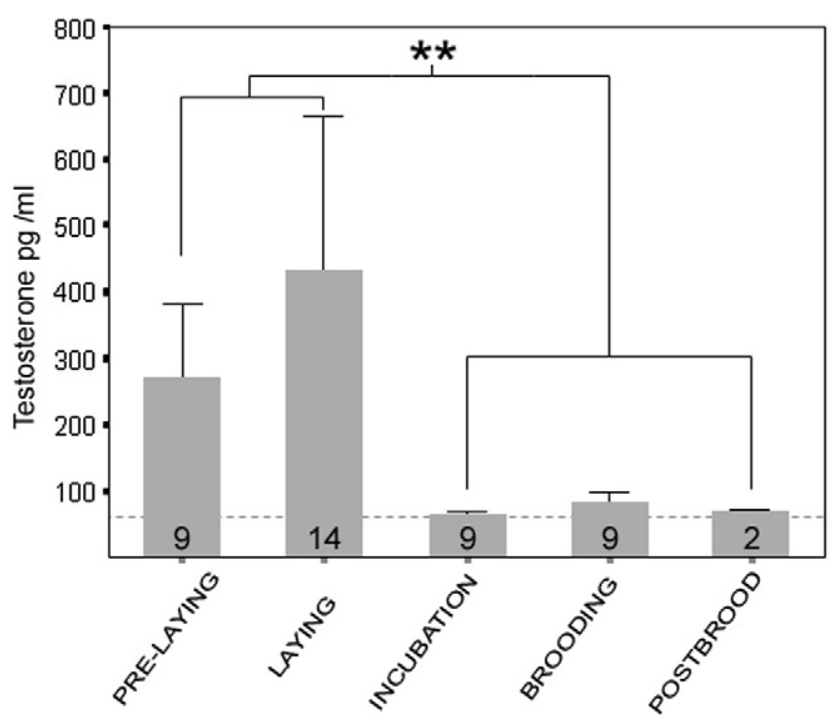

Fig. 2. Seasonal changes in the circulating levels of testosterone (mean \pm 1 standard error) in breeding male black kites ( $\mathrm{n}=43$ individuals) across different stages of the reproductive cycle. Numbers indicate sample size, the dotted line shows the detection limit of the assay, and the solid lines group study periods having statistically similar steroid levels, unless marked with asterisks (** denotes $\mathrm{P}<0.01)$.

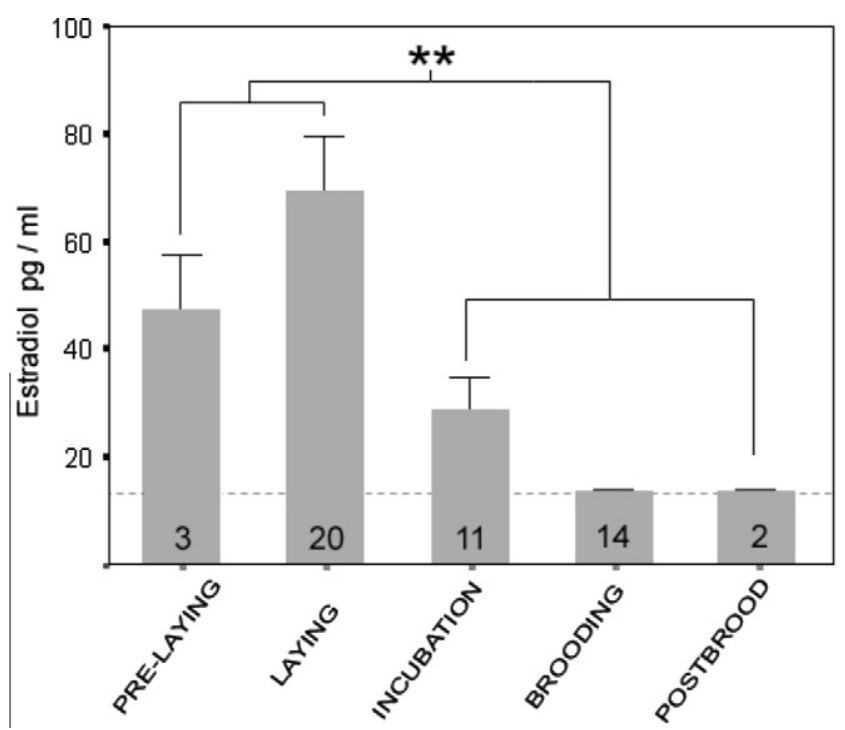

Fig. 3. Seasonal changes in the circulating levels of estradiol (mean \pm 1 standard error) in breeding female black kites ( $\mathrm{n}=50$ individuals) across different stages of the reproductive cycle. Numbers indicate sample size, the dotted line shows the detection limit of the assay, and the solid lines group study periods having statistically similar steroid levels, unless marked with asterisks (** denotes $\mathrm{P}<0.01)$.

an overall seasonal increase, progesterone reached maximum titres during Incubation $\left(\mathrm{v}_{1}{ }_{1}=9.32, \mathrm{P}<0.01\right)$ and maintained average, statistically indistinguishable levels prior to and after this stage $\left(\mathrm{V}^{2}{ }_{1}=0.28, \mathrm{P}=0.96\right.$, Fig. 5). Restricting the analyses to the periods when peak progesterone levels are reached (i.e. Incubation and Post-brooding), the GLM revealed a significant interaction between sex and stage $\left(\mathrm{v}^{2}{ }_{1}=6.23, \mathrm{P}<0.05\right)$. However, in absolute terms peak progesterone levels in incubating females $(7.52 \pm 1.6 \mathrm{pg} / \mathrm{ml})$ were virtually identical to the peak levels of males during Postbrooding $(7.73 \pm 1.9 \mathrm{pg} / \mathrm{ml})$.

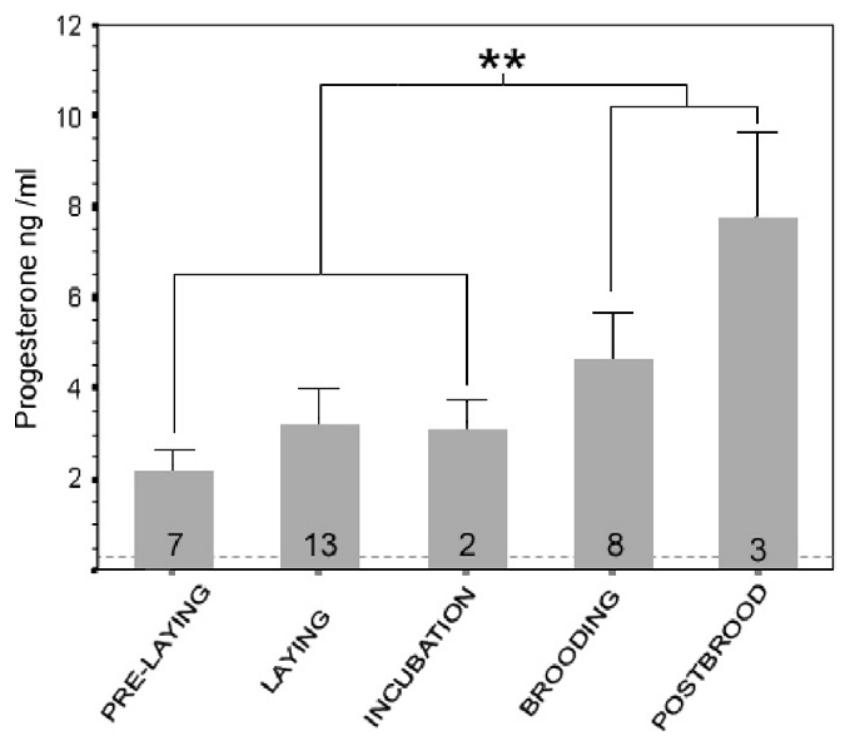

Fig. 4. Seasonal changes in the circulating levels of progesterone (mean \pm 1 standard error) in breeding male black kites $(n=33$ individuals) across different stages of the reproductive cycle. Numbers indicate sample size, the dotted line shows the detection limit of the assay, and the solid lines group study periods having statistically similar steroid levels, unless marked with asterisks (** denotes $\mathrm{P}<0.01)$. 


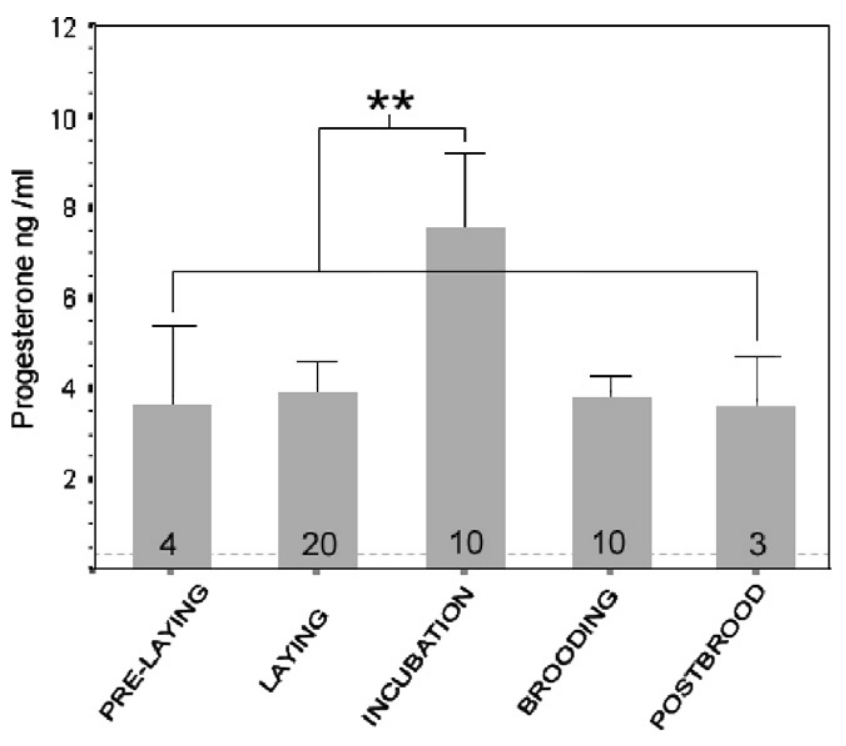

Fig. 5. Seasonal changes in the circulating levels of progesterone (mean \pm 1 standard error) in breeding female black kites ( $n=47$ individuals) across different stages of the reproductive cycle. Numbers indicate sample size, the dotted line shows the detection limit of the assay, and the solid lines group study periods having statistically similar steroid levels, unless marked with asterisks (** denotes $\mathrm{P}<0.01)$.

\section{Discussion}

Supporting our first prediction, circulating levels of testosterone in male black kites were elevated during Pre-laying and Laying and decreased drastically from Incubation onwards (Fig. 2). This result is consistent with studies reporting a positive association between plasma androgens and spermatogenesis (Hirschenhauser et al., 1999; Wingfield and Farner, 1993) as well as typical sexual behaviors such as mating displays (Cherel et al., 1994; McQuenn et al., 1999; Saint Jalme et al., 1996) and nest building (Mays et al., 1991; Schoech et al., 1991; Silver and Cooper, 1993). Elevated testosterone has also been shown to increase plasma carotenoids and facilitate the expression of sexually selected traits (Blas et al., 2006). Black kites, as most Accipitridae birds, have bright orange and yellow ceres and legs, with the colour intensity being positively related to circulating carotenoid levels (Blas, 2002; authors, unpublished manuscript). The testosterone elevations recorded during the early stages of reproduction may thus be associated with the development of visual signals which are potentially used in sexual selection (Blas et al., 2006). Although the highest titres of testosterone match the periods of highest sexual activity, some of the behavioral effects generally attributed to testosterone (such as the facilitation of copulation behaviour and intraspecific aggression; Wingfield and Hahn, 1994; McDonald et al., 2001; Ketterson and Nolan, 1994) extend in black kites thorough the whole reproductive season. Males of black kites and of closely related species maintain high rates of intrasexual aggression after laying, and copulating behavior in most raptors extends long after the fertile period (Koga and Shiraishi, 1994; Mougeot, 2000; Negro and Grande, 2001). All this suggests that male sexual behavior can be also regulated independently of androgens or, alternatively, that following egg laying males restrict testosterone elevations to short bouts (e.g. during copulation and aggressions) as proposed by the "Challenge hypothesis” (Goymann et al., 2007; Wingfield et al., 1987). The low testosterone levels that were maintained by males during Incubation and Brooding are consistent with the inhibitory effects that this hormone exerts on the expression of parental behaviours (hypothesis 2; Steiger et al., 2006; Wingfield et al., 2001; McQuenn et al., 1999).
Absolute levels of testosterone were far below the values described in the vast majority of wild temperate species studied to date (Wingfield and Farner, 1993). Peak levels during Pre-laying (i.e. seasonal maximum) were only comparable to those recorded in Harriś hawks (Mays et al., 1991), Cape cormorants Phalacrocorax capensis (Berry et al., 1979) and some tropical birds (Hau and Wingfield, 1999), supporting the hypothesis 4 that relatively low levels of sex steroids occur in species showing high rates of inter-year fidelity to territories and mates (Mays et al., 1991), as occurs in black kites (Forero et al., 1999).

With regard to circulating estradiol, seasonal changes in female kites were similar to the patterns observed for testosterone in males, but the decrease following egg laying was more gradual, showing intermediate estradiol titres during Incubation (Fig. 3). The high levels recorded during Pre-laying and Laying support our prediction 1, consistent with studies showing elevated titres during periods of yolk formation and deposition (Wingfield and Farner, 1993), and supporting the role of this hormone in the regulation of ovarian recrudescence, vitellogenesis, and the expression of nesting and sexual behaviours (Wingfield, 1980; Harvey et al., 1997). Similarly, the gradual decreases in estradiol that female kites showed after Laying could be related to gonadal regression (Groscolas et al., 1986). The intermediate levels recorded during Incubation may suggest a role of this hormone in the facilitation of parental behavior as indicated by some studies (Silver and Cooper, 1993; Cherel et al., 1994; Hector et al., 1996). However, our results only provide partial support for the hypothesis that estradiol levels facilitate parental care, as circulating levels were consistently low during Brooding.

With regard to progesterone levels, female kites showed a single peak during Incubation (Fig. 5). The effects of this hormone on avian reproductive behaviour are to a large extent unknown, and often contradictory among studies. While some species seem to display two seasonal peaks associated with egg Laying and Incubation (Bluhm et al., 1983; Donham, 1979), others display a single peak during Laying (Rehder et al., 1986; Dawson, 1983; Péczely and Pethes, 1982; Péczely and Pethes, 1979; Wingfield et al., 1982), or during hatching (Davis et al., 1995). Our results suggest a role of this hormone in the expression of parental behavior. Contrary to females, male progesterone levels showed a gradual increase as the reproductive season progressed and maximum levels were attained during the Post-brooding period (Fig. 4). This pattern contrasts with the reported seasonal changes in male gulls (showing the opposite trend, Wingfield et al., 1982), and other species where progesterone levels remained low throughout the reproductive cycle (Péczely and Pethes, 1979; Péczely and Pethes, 1982). However, despite the fact that peak levels in females and males were attained in different periods, the temporal pattern resembled sex-related changes in parental activities. Incubation is predominantly performed by female black kites, while males perform most of the hunting activities and provide food to their partner (Cramp and Simmons, 1980). In contrast, during the Post-brooding period male black kites take a predominant role in fledgling care, while females often abandon the territory at this time (Bustamante and Hiraldo, 1989). The fact that peak progesterone levels are attained in females during Incubation and in males during Post-brooding suggests that this hormone could be involved in the expression of parental behaviors. This hypothesis is also supported by recent studies showing that non-breeding females have lower circulating progesterone levels compared to breeding females during the incubation period, but not at other times of the cycle (Blas and Hiraldo, 2010).

Finally, an interesting observation was the relatively high levels of male testosterone and female estradiol displayed early in the Pre-laying period, even during the first week of March. The elevations were similar in magnitude to the recorded peak titres at 
Laying, suggesting that physiological readiness for reproduction is probably attained before arriving to the breeding grounds (Astheimer and Grau, 1985; Groscolas et al., 1986). This is consistent with the observation that many territories monitored twice a day during the spring settlement period, appear to be suddenly occupied by a mated pair rather than by a sequence of individual partners (authors' unpublished data). Considering that black kites are highly social year-round, it is plausible that experienced pairs interact during spring migration. Because mate-mate interactions constitute supplementary essential information required for attaining gonadal development (Mantei et al., 2008; Stevenson et al., 2008) the initiation of such behaviours prior to arrival could be highly adaptive, as it would allow experienced mates to optimize a breeding season constrained within a relatively short time-frame in migratory species. Such social bonding during migration would give further breeding advantage to those pairs that are capable of migrating early, and this is consistent with the observation that early arrival to the breeding grounds leads to early laying and higher reproductive output (Sergio et al., 2007a; Blas et al., 2009).

In conclusion, the reported changes of circulating testosterone and estradiol levels support a set of predictions based on phylogenetically distant species, and suggest that these patterns apply widely to seasonally breeding birds (for other raptors see Mays et al., 1991; Meijer and Schwabl, 1989; Rehder et al., 1986; Rehder et al., 1988). However, contrary to other species, our results suggest that progesterone is involved in the expression of parental behaviour in both males and females, revealing an area of investigation that is ripe for future experimental studies.

\section{Acknowledgments}

We thank G. García, S. Cabezas, R. Baos, A. Sánchez, M. Guerrero, F.J. Vilches and L. Hillström for help in the field, F. Recio, J. Estepa and L.M. Torres for help in the laboratory, L. Lavigne and E. Quiring for revising the text and two anonymous referees for comments and suggestions on earlier drafts. Funding was provided by CSIC and the European union in a I3P Grant to JB, and by the research projects PB96-0834 of the Dirección General de Investigación Científica y Tecnológica, CGL2008-01781/BOS of the Ministerio de Ciencia e Innovación, JA-58 of the Consejería de Medio Ambiente de la Junta de Andalucía and by the Excellence Project RNM 1790 and RNM 03822 of the Junta de Andalucía.

\section{References}

Astheimer, L.B., Grau, C.R., 1985. The timing and energetic consequences of egg formation in the Adelie penguin. Condor 87, 256-268.

Baos, R., Blas, J., 2009. Adrenocortical toxicology in birds: environmental contaminants and the avian response to stress. In: Harvey, P.W., Everett, D., Springall, C. (Eds.), Adrenal toxicology, Target organ toxicology series. Informa Healthcare USA, Inc., New York, pp. 257-293.

Berry, H.H., Millar, R.P., Louw, G.N., 1979. Environmental cues influencing the breeding biology and circulating levels of various hormones and triglycerides in the Cape cormorant. Comparative Biochemistry and Physiology 62A, 879-884.

Bird, D.M., Buckland, R.B., 1976. The onset and duration of fertility in the American kestrel. Canadian Journal of Zoology 54, 1595-1597.

Blas, J. 2002. Edad y reproducción en el milano negro (Milvus migrans). Ph.D. Thesis, Universidad Autónoma, Madrid.

Blas, J., Baos, R., 2008. Stress in the nest: causes and consequences of adrenocortical secretion in developing birds. In: Capaldo, A. (Ed.), Recent Advances in Nonmammalian Adrenal Gland Research. Research Signpost, Kerala, pp. 89-128. Available from: http://www.trnres.com/.

Blas, J., Hiraldo, F., 2010. Proximate and ultimate factors explaining floating behavior in long-lived birds. Hormones and Behavior 57, 169-176.

Blas, J., Pérez-Rodríguez, L., Bortolotti, G., Viñuela, J., Marchant, T.A., 2006. Testosterone increases bioavailability of carotenoids: Insights into the honesty of sexual signalling. Proceedings of the National Academy of Sciences USA 103, 18633-18637.

Blas, J., Sergio, F., Hiraldo, F., 2009. Age-related improvement in reproductive performance in a long-lived raptor: a cross-sectional and longitudinal study. Ecography 32, 647-657.
Bluhm, C.K., Phillips, R.E., Burke, W.H., 1983. Serum levels of LH, prolactin, estradiol, and progesterone in laying and non laying canvasback ducks (Aythya valisineria). General and Comparative Endocrinology 52, 1-16.

Bustamante, J., Hiraldo, F., 1989. Post-fledging dependence period and maturation of flight skills in the black kite Milvus migrans. Bird Study 36, 199-204.

Cramp, S., Simmons, K.E.L., 1980. The Birds of the Western Palearctic. Oxford University Press, Oxford.

Cherel, Y., Mauget, R., Lacroix, A., Gilles, J., 1994. Seasonal and fasting-related changes in circulating gonadal steroids and prolactin in king penguins, Aptenodyptes patagonicus. Physiological Zoology 67, 1154-1173.

Davis, L.S., Cockrem, J.F., Miller, G.D., Court, G.S., 1995. An incubation timer for seabirds: progesterone and its relationship to hatching in Adelie penguins. Emu 95, 245-251.

Dawson, A., 1983. Plasma gonadal steroid levels in wild starlings (Sturnus vulgaris) during the annual cycle and in relation to the stages of breeding. General and Comparative Endocrinology 49, 286-294.

del Hoyo, J., Elliot, A., Sargatal, J., 1994. Handbook of the Birds of the World. Lynx Edicions, Barcelona.

Donham, R.S., 1979. Annual cycle of plasma luteinizing hormone and sex hormones in male and female mallards (Anas platyrhynchos). Biology of Reproduction 21, 1273-1285.

Elbetieha, A., Da'as, S.I., 2003. Assessment of antifertility activities of abamectin pesticide in male rats. Ecotoxicology and Environmental Safety 55 (3), 307313.

Ellegren, H., 1996. First gene on the avian W chromosome (CHD) provides a tag for universal sexing of non-ratite birds. Proceedings of the Royal Society of London Series B 263, 1635-1641.

Fivizzani, A.J., Oring, L.W., 1986. Plasma steroid hormone levels in free-living spotted sandpipers, Actitis macularia. Biology of Reproduction 35, 1195-1201.

Forero, M.G., Donazar, J.A., Blas, J., Hiraldo, F., 1999. Causes and consequences of territory change and breeding dispersal distance in the black kite. Ecology 80, 1298-1310.

Forero, M.G., Donázar, J.A., Hiraldo, F., 2002. Causes and fitness consequences of natal dispersal in a population of black kites. Ecology 83, 858-872.

Goymann, W., Landys, M.M., Wingfield, J.C., 2007. Distinguishing seasonal androgen responses from male-male androgen responsiveness - revisiting the challenge hypothesis. Hormones and Behavior 51 (4), 463-476.

Groscolas, R., Jallageas, M., Goldsmith, A., Assenmacher, I., 1986. The endocrine control of reproduction and molt in male and female emperor (Aptenodites forsteri) and Adelie (Pygoscelis adeliae) penguins. I. Annual changes in plasma levels of gonadal steroids and LH. General and comparative endocrinology 62, 43-53.

Harvey, S., Scanes, C.G., Phillips, J.G., 1997. Avian reproduction. In: Chester Jones, I., Ingleton, P.M., Phillips, J.G. (Eds.), Fundamentals in Comparative Vertebrate Endocrinology. Plenum, New York, pp. 125-185.

Hau, M., Wikelski, M., Soma, K.K., Wingfield, J.C., 2000. Testosterone and year-round territorial aggression in a tropical bird. General and Comparative Endocrinology 117, 20-33.

Heath, J.A., Frederick, P.C., Edwards, T.M., Guillette, L.J., 2003. Reproductive physiology of free-living white ibises (Eudocimus albus) in the Florida Everglades. General and Comparative Endocrinology 133, 118-131.

Hector, J.A., Goldsmith, A.R., 1985. The role of prolactin during incubation: comparative studies in three Diomedea species. General and Comparative Endocrinology 60, 236-243.

Hector, J.A.L., Croxall, J.P., Follet, B.K., 1996. Reproductive endocrinology of the wandering albatross Diomedea exulans in relation to biennial breeding and deferred sexual maturity. Ibis 128, 9-22.

Hirschenhauser, K., Möstl, E., Kotrschal, K., 1999. Seasonal patterns of sex steroids determined from faeces in different social categories of greylag geese (Anser anser). General and Comparative Endocrinology 114, 67-79.

Ketterson, E.D., Nolan Jr., V., 1994. Male parental behavior in birds. Annual Reviews of Ecology and Systematics 25, 601-628.

Koga, K., Shiraishi, S., 1994. Copulation behavior of the black kite Milvus migrans in Nagasaki peninsula. Bird Study 41, 29-36.

Maney, D.L., 2008. Endocrine and genomic architecture of life history trade-offs in an avian model of social behavior. General and Comparative Endocrinology 157, 275-282.

Mantei, K.E., Ramakrishnan, S., Sharp, P.J., Buntin, J.D., 2008. Courtship interactions stimulate rapid changes in GnRH synthesis in male ring doves. Hormones and Behavior 54, 669-675.

Mays, N.A., Vleck, C.M., Dawson, J., 1991. Plasma LH, steroid hormones, behavioral role, and nest stage in cooperatively breeding Harriś hawks. The Auk 108, 619637.

McCullagh, P., Nelder, J.A., 1989. Generalized Linear Models. Chapman and Hall, New York.

McDonald, P.G., Buttemer, W.A., Astheimer, L.B., 2001. The influence of testosterone on territorial defence and parental behavior in male free-living rufous whistlers, Pachycephala rufiventris. Hormones and Behavior 39, 185-194.

McQuenn, S., Davis, L.S., Young, G., 1999. Sex steroid and corticosterone levels of Adélie penguins (Pygoscelis adeliae) during courtship and incubation. General and Comparative Endocrinology 114, 11-18.

Meijer, T., Schwabl, H., 1989. Hormonal patterns in breeding and nonbreeding kestrels, Falco tinnunculus: field and laboratory studies. General and comparative endocrinology 74, 148-160.

Mougeot, F., 2000. Territorial intrusions and copulation patterns in red kites, Milvus milvus, in relation to breeding density. Animal Behaviour 59, 633-642. 
Negro, J.J., Grande, J.M., 2001. Territorial signalling: a new hypothesis to explain frequent copulation in raptorial birds. Animal Behaviour 62, 803-809.

Nelson, R.J., 2005. An Introduction to Behavioral Endocrinology. Sinauer Associates, Inc., Sunderland.

Péczely, P., Pethes, G., 1979. Alterations in plasma steroid concentrations in the collared dove (Streptopelia decaocto) during the sexual maturation and reproduction cycle. Acta Physica Academiae Scientarium Hungarica 54, 161-170.

Péczely, P., Pethes, G., 1982. Seasonal cycle of gonadal, thyroid, and adrenocortical function in the rook (Corvus frugileus). Acta Physica Academiae Scientarium Hungarica 59, 59-73.

Rehder, N.B., Bird, D.M., Lague, P.C., 1988. Plasma androgen levels and body weights for breeding and non-breeding American kestrels. Condor 90, 555-560.

Rehder, N.B., Bird, D.M., Laguë, P.C., 1986. Variations in plasma corticosterone, estrone, estradiol, and progesterone concentrations with forced renesting, molt and body weight of captive female American kestrels. General and Comparative Endocrinology 62, 386-393.

Saint Jalme, M., Williams, J., Mickaelian, I., Paillat, P., 1996. Seasonal variation of LH, sex steroids, body mass, molt, display, and laying in two species of houbara bustard, Chlamydotis unduklata macqueenii and Chlamydotis unduklata undulata, housed in outdoor cages under natural conditios. General and Comparative Endocrinology 102, 102-112.

Schoech, S.J., Mumme, R.L., Moore, M., 1991. Reproductive endocrinology and mechanisms of breeding inhibition in cooperatively breeding Florida scrub jays (Aphelocoma C. Coerulescens). The Condor 93, 354-364.

Sergio, F., Blas, J., Forero, M., Fernández, N., Donázar, J.A., Hiraldo, F., 2005. Preservation of wide-ranging top predators by site-protection: Black and red kites in Doñana National Park. Biological Conservation 125, 11-21.

Sergio, F., Blas, J., Forero, M.G., Donázar, J.A., Hiraldo, F., 2007a. Sequential settlement and site-dependence in a migratory raptor. Behavioral Ecology 18, 811-821.

Sergio, F., Blas, J., Hiraldo, F., 2009. Predictors of floater status in a long-lived, migratory bird: a cross-sectional and longitudinal test of hypotheses. Journal of Animal Ecology 78, 109-118.

Sergio, F., Blas, J., Forero, M.G., Donázar, J.A., Hiraldo, F., 2007b. Size-related advantages for reproduction in a slightly dimorphic raptor: opposite trends between the sexes. Ethology 113, 1141-1150.

Silver, R., Cooper, M., 1993. Avian behavioral endocrinology. Bioscience 33, $567-$ 572.

Steiger, S.S., Goymann, W., Kempenaers, B., 2006. Plasma steroid hormones in two Arctic-breeding shorebirds: monogamy versus polygyny. General and Comparative Endocrinology 147, 133-140.
Stevenson, T.J., Bentley, G.E., Ubuka, T., Arckens, L., Hampson, E., MacDougallShackleton, S.A., 2008. Effects of social cues on GnRH-I, GnRH-II, and reproductive physiology in female house sparrows (Passer domesticus). General and Comparative Endocrinology 156, 385-394.

Viñuela, J. 1991. Ecología reproductiva del Milano Negro (Milvus migrans) en el Parque Nacional de Doñana. Madrid. Ph.D. Thesis, Universidad Complutense de Madrid, Madrid.

Viñuela, J., Bustamante, J., 1992. Effect of growth and hatching asynchrony on the fledging age of black and red kites. The Auk 109, 748-757.

Viñuela, J., Ferrer, M., 1997. Regulation of growth in red kites and imperial eagles. Willson Bulletin 109, 92-101.

Hau, M., Wingfield, J.C., 1999. Social instability increases testosterone year-round in a tropical bird. Proceedings of the Royal Society of London B 266, 1-6.

Wingfield, C., Ball, G., Dufty, J., Hegner, R., Ramenofsky, M., 1987. Testosterone and aggression in birds: tests of the "Challenge hypothesis". American Scientist 75, $602-608$.

Wingfield, J.C., 1980. Fine temporal adjustment of reproductive functions. In: Epple, A., Stetson, M.H. (Eds.), Avian Endocrinology. Academic Press, London, pp. 363389.

Wingfield, J.C., 1983. Environmental and endocrine control of reproduction: an ecological approach. In: Mikami, S.I., Ishii, S., Wada, M. (Eds.), Avian Endocrinology: Environmental and Ecological Aspects. Springer, Tokyo, Berlin.

Wingfield, J.C., 2008. Comparative endocrinology, environment and global change. General and Comparative Endocrinology 157, 207-216.

Wingfield, J.C., Farner, D.S., 1993. Endocrinology of reproduction in wild species. In: Farner, D.S., King, J.R., Parkes, K.C. (Eds.), Avian Biology. Academic Press, New York, pp. 163-327.

Wingfield, J.C., Hahn, T.P., 1994. Testosterone and territorial behaviour in sedentary and migratory sparrows. Animal Behaviour 47, 77-89.

Wingfield, J.C., Lynn, S., Soma, K.K., 2001. Avoiding the 'costs' of testosterone: ecological bases of hormone-behavior interactions. Brain, Behavior and Evolution 57, 239-251.

Wingfield, J.C., Newman, A.L., Hunt, G.L., Farner, D.S., 1982. Endocrine aspects of female-female pairing in the western gull (Larus occidentalis wymani). Animal Behavior 30, 9-22.

Wingfield, J.C., Silverin, B., 2002. Ecophysiological studies of hormone-behavior relations in birds. In: Pfaff, D.W., Arnold, A.P., Etgen, A.M., Fahrbach, S.E., Rubin, R.T. (Eds.), Hormones, Brain and Behavior. Elsevier Science, USA, pp. 587-647.

Wingfield, J.C., Visser, M.E., Williams, T.D., 2008. Integration of ecology and endocrinology in avian reproduction: a new synthesis. Philosophical Transactions of the Royal Society of London Series B 363, 1581-1588. 